\title{
Study on Medical English Writing with the Automatic Essay Scoring through Translation
}

\section{Junling Wang}

Ningxia Medical University, Ningxia, Yinchuan, 750004

\author{
Keywords: Automated Essay Scoring, Medical English, Translation Writing
}

\begin{abstract}
Through application of an Automated Essay Scoring in medical English writing class, the purpose of this paper is to research the students' attitude towards using the online formative assessment evaluation tool "Juku Correcting network" and the relationship between the writing practice and attitude. The one-year teaching experiment and questionnaires and the interview data show that through the use of the Automated Essay Scoring the students' overall medical English writing level was raised and that the students held affirmative attitudes towards the role of online scoring in medical English writing; word number in writing and the number of times for revising were significantly increased; there was positive correlation between the proportion of using complex words and the students' English proficiency. On the basis of this research, this paper puts forward some suggestions for the teaching of medical English writing and recommendations for improvement of teachers and system developers.
\end{abstract}

\section{Introduction}

The Outline of the National Medium and Long-Term Education Reform and Development Plan (2010-2020) states that "Information technology has a revolutionary impact on education development and must be given high priority." The "Outline" also states that "by 2020, we should basically build all levels of urban and rural areas education information system for all kinds of schools, promote education content and teaching methods and realize modernization of methods ". "College English Curriculum Requirements" clearly requires the use of information technology in college English teaching to improve teaching effectiveness so that English teaching will not be limited by time and place and will develop in the direction of individualized and autonomous learning. Therefore, to explore how to effectively use standardized assessment tools based on information technology to improve teaching effectiveness is not only a topic of concern to academics but also education authorities [1].

\section{Writing automatic assessment system}

Writing automated review system (Automated Essay Scoring, AES) is the use of computer technology to assess and score composition, its research and application of computer-aided foreign language writing teaching has become a hot spot at home and abroad.

Medical English writing plays an extremely important role in the cultivation of professional English teaching for medical students. Its content mainly includes the research papers, abstracts, medical literature reviews, case reports and case writing. In order to reduce the difficulty of medical English writing, in the following study we take translation writing, that is, to provide students with Chinese medical writing materials, require students to directly translate as a way of English writing practice.

There are more than ten kinds of automatic evaluation systems successfully developed and put into use abroad. The most representative ones are Project Essay Grade (PEG), IEA (Intelligent Essay Assessor) and E-rater, as well as the newly developed Criterion, My Access and Writing Roadmap. Domestic research in this direction has lasted for nearly 40 years. Facts have proved that EG, IEA and E-rater are mostly used in English-speaking writing assessment and feedback, and their applicability to English writing by Chinese students is not so strong. The current batch of 
colleges and universities in China promote the use of Juku correcting network (http://www.pigai.org), hereinafter referred to as approved network, which is an online smart correction system to SAAS (software as a service) for teachers and English learning Provide online composition of English e-mail automatically modify services.

\section{Automatic writing review system medical English translation writing teaching research}

This study is an attempt to integrate modern information technology into medical English writing. The initial belief is that the introduction of technology depends on people to grasp. Such attempts are likely to bring about teaching reform and the evolution of teachers and students' beliefs and practices. Therefore, this study aims to investigate the students' attitudes towards using "online assessment" and the relationship between attitudes and their writing performance through an experiment that uses automatic writing evaluation system in medical English translation writing teaching. The performance of college students writing involves two aspects: First, the number of writing, that is, students 'writing frequency. The second is the quality of writing, that is, the students' writing text evaluation results. Grading of writing texts uses two mechanisms, the holistic rating and analytical rating provided by the rating website. The correlation between attitude and writing performance is based on a survey of students' attitudes and the correlation between writing frequency and composition score.

The subjects were grade two medical students, four natural classes, a total of 160 students (experimental group 89; control group 71). This study lasts two semesters, each four months, with the same steps.

Before the experiment, two groups of students took part in a standardized medical essay "introduction" translation writing. The essay topic was extracted from (Medical English Writing and Translation, Shandong University) and the test time was 35 minutes. The aim was to understand the students' English skills before the experiment. Students in the experimental group are required to be familiar with the student guide and essay grading standards for network modification system in the first week. The teachers participating in the experiment accepted the technical training of using modified network and of the teaching of medical English translation writing before the experiment started.

In the experiment, the experimental group practiced writing by using the modified network, and an average of three to four exercises were conducted every four months in batch practice. The forms were mainly theses and abstracts of theses. Control group teaching as usual, does not apply to modify the network. In addition, teachers provide a weekly medical essay topic for students to choose freely.

At the end of the experiment, two groups of students participated in a standardized English writing test based on the revised network. The selection of the essay questions before and after the test follows AB Cross-over Sampling to eliminate the interference of time and factors of different essay topics, so as to ensure that the average performance of the two groups of students is comparable. The scores of the essay questions were first reviewed by a reviewer and then re-evaluated by trained language teaching specialists to ensure the fairness of the ratings.

Another quantitative research method used in this study is the attitude questionnaire. Qualitative research methods include student interviews. Attitudes towards the use of online formative assessment tools include the following three dimensions: attitude toward writing, attitude towards the use of computers for writing, and attitude towards the use of retouching. Before and after the test, students in the experimental group were asked to fill in the questionnaire about the same attitude online, so as to understand whether the students' attitudes after using the modified network have changed. After the experiment, according to the results of the quantitative research, the researchers selected several students who had changes in attitude, quantity and quality of writing to interview respectively. The content mainly focused on the students' experience of using the modified net and how they used the system to assist writing about half an hour. The data obtained were used as the supplement and explanation of the quantitative study.

After the experiment, 81 questionnaires were collected, accounting for $91 \%$ of the total number 
of experimental groups. Questionnaire data and scores are unified input SPSS 21.0, the analysis found:

\begin{tabular}{|c|c|c|}
\hline Table I problem & Mean & SD (standard deviation) \\
\hline $\begin{array}{c}\text { Modification network's role } \\
\text { in writing }\end{array}$ & 3.6100 & .71432 \\
\hline
\end{tabular}

It can be seen from Table 1 that students hold a positive attitude towards the role of the modification network in English writing. Interview further proved this issue. Eighty-three percent of students thought that they were curious about the function of modification network before the experiment. However, they began to realize many advantages of modification network and began to modify their composition according to the suggestions of the network. The number of writing words increased significantly and the number of modification was more. $57 \%$ of students modify their writing 2-3 times, $21 \%$ of the students more than 4 times. Some students with strong motivation to learn can even modify to 28 times.

"I think the network is quite easy to modify, each composition submission is ranked, like me occasionally like to find a variety problems and to enhance my points and rankings. I would focus on the four aspects suggested by the network: vocabulary, sentences, text structure, content to find room for improvement.”

(Student 1, Interview)

"One of the advantages of modified web is that it lets me know what I can do to improve my overall composition. Each time when the composition scores improves by 0.5 points or rankings improve one number, I would be extremely excited and conduct repeated modifications. The syntax error function is quite good, every time when I first modify my paper, I would see what grammatical errors are, and then think of ways to enhance my writing.”

(Student 2, Interview)

In addition, the results of experimental group and control group in pre-test and post-test can also see the impact of the tool on students' performance:

\begin{tabular}{|c|c|c|c|c|c|c|c|c|c|c|}
\hline \multicolumn{3}{|c|}{$\begin{array}{l}\text { Test Group: } 1 \\
\text { Control group: } 2\end{array}$} & \multicolumn{4}{|c|}{$\begin{array}{c}\text { Table II experimental group and control group comparison of } \\
\text { pre-test scores }\end{array}$} & \multicolumn{4}{|c|}{$\begin{array}{c}\text { Table } 3 \text { experimental group and control group } \\
\text { post-test scores comparison Note: } * \mathrm{P}<0.5 ; * * \mathrm{P}<.01\end{array}$} \\
\hline $\begin{array}{l}\text { Evaluation } \\
\text { index }\end{array}$ & Group & Num & $\begin{array}{l}\text { average } \\
\text { value }\end{array}$ & $\begin{array}{l}\text { Standard } \\
\text { deviation }\end{array}$ & $\begin{array}{l}\text { Between } \\
\text { groups } \\
\text { difference } \\
\text { (T value) }\end{array}$ & $\begin{array}{c}\text { Significance } \\
\text { (Two-tailed } \\
\text { test) }\end{array}$ & $\begin{array}{l}\text { average } \\
\text { value }\end{array}$ & $\begin{array}{l}\text { Standard } \\
\text { deviation }\end{array}$ & $\begin{array}{l}\text { Between } \\
\text { groups } \\
\text { difference } \\
\text { (T value) }\end{array}$ & $\begin{array}{c}\text { Significance } \\
\text { (Two-tailed } \\
\text { test) }\end{array}$ \\
\hline content & 1 & 89 & 2.4024 & .95291 & .374 & .709 & 2.66 & .8863 & 4.309 & $* * .000$ \\
\hline \multirow{2}{*}{ structure } & 1 & 89 & 2.6548 & .82498 & \multirow{2}{*}{1.003} & \multirow{2}{*}{.319} & 2.945 & .7445 & \multirow{2}{*}{4.359} & \multirow{2}{*}{$* * .000$} \\
\hline & 2 & 71 & 2.4171 & 1.28955 & & & 2.650 & .6118 & & \\
\hline \multirow[t]{2}{*}{ Style } & 1 & 89 & 2.7405 & .92395 & \multirow{2}{*}{.868} & \multirow{2}{*}{.388} & 2.980 & .7325 & \multirow{2}{*}{4.426} & \multirow{2}{*}{$* * .000$} \\
\hline & 2 & 71 & 2.5220 & 1.33595 & & & 2.624 & .6480 & & \\
\hline \multirow{2}{*}{ vocabulary } & 1 & 89 & 2.3167 & .77803 & \multirow{2}{*}{.532} & \multirow{2}{*}{.596} & 2.606 & .8010 & \multirow{2}{*}{4.819} & \multirow{2}{*}{$* * .000$} \\
\hline & 2 & 71 & 2.1976 & 1.21789 & & & 2.242 & .6589 & & \\
\hline syntax & 1 & 89 & 2.6167 & .82843 & 1.077 & .285 & 2.930 & .7366 & 4.717 & $* * .000$ \\
\hline \multirow{2}{*}{ specification } & 1 & 89 & 2.7667 & .83393 & \multirow{2}{*}{1.427} & \multirow{2}{*}{.157} & 2.976 & .7935 & \multirow{2}{*}{4.141} & \multirow{2}{*}{$* * .000$} \\
\hline & 2 & 71 & 2.4244 & 1.30533 & & & 2.647 & .6442 & & \\
\hline \multirow[t]{2}{*}{ Total score } & 1 & 89 & 2.5829 & .81203 & \multirow{2}{*}{.907} & \multirow{2}{*}{.367} & 2.861 & .7392 & 484 & ** $* 000$ \\
\hline & 2 & 71 & 2.3715 & 1.26782 & & & 2.511 & .6174 & 4.844 & .000 \\
\hline
\end{tabular}

As can be seen from Table 2, there is no significant difference between the experimental group and the control group in the pretest results. As can be seen from Table III, after two semesters in the post-test, the results were significantly different, the experimental group's score was significantly higher than that of the control group. Therefore, we can conclude that the overall level of medical English writing is improved among the modification web-based students.

In terms of individual differences, the analysis shows that nearly half of the students, all females, can make full use of network suggestions and think positively. The proportion of using complicated vocabulary is directly proportional to the students' English level, that is, the students with lower English level have a higher proportion of using the common vocabularies. This result is consistent 
with the findings of Tang Jinlan et al. (2012). The result of the research proves that correcting network has a positive effect on English writing and students' attitudes toward writing network are positively correlated with writing performance.

\section{The experimental revelation and teaching suggestions}

Modification network provides students with an independent learning platform. Hence, teachers should strengthen supervision and guidance of student self-learning. Almost all the students who participated in this experiment fully affirmed the positive effect of correcting network. They think that correcting network has created a practicing platform that will be of great help to their writing ability. But there are also some students who reflect they just casually take a few minutes from the internet to copy and paste essay and this work can get a high score. This phenomenon is especially common among students with lower English proficiency. Teachers should strengthen their supervision and motivation. They should be more concerned about and often counseled these students. At the same time, I hope to amend the network system and increase some anti-plagiarism [2].

Computer-aided teaching can not completely replace the traditional teaching, so teachers should actively involve, providing timely guidance and help. To a large extent, the use of the revised network can reduce the workload of teachers and help teachers to understand students' English writing more intuitively. However, due to the different degrees of students, there is also a difference in the ability to understand the diagnostic feedback of online pharmacies. Students reflect that sometimes they are confused about advice from network on how to modify the essay, especially with regard to grammar. Teachers should summarize the problems that appear in the essay in time, select typical cases, and combine the errors pointed out by the revising network to further provide the feedback and supplementation in class teaching so as to help the students and solve their problems. Teachers can also organize class discussions, allowing students to choose their own work, to discuss the four dimensions of revising network, to achieve the purpose of improvement. At the same time, it is suggested that the approval network be classified according to the students' English proficiency, and a personalized improvement suggestion with appropriate difficulty degree should be given.

For the medical English writing style, there are still many imperfections in the system. Due to the modification network's suggestion on the frequency of collocation used by students in the corpus, the students made great progress in terms of vocabulary and content. Modifications made by the network mostly focused on misspellings or to alternative synonyms, but does not involve the professional thesaurus and medical English stylistic features. It is necessary for teachers to increase medical English vocabularies in future teaching so as to enable students to store more linguistic materials and ensure the students' effective language output. In particular, it is necessary to further emphasize the common sentence patterns and fixed collocations of medical English. At the same time, we are expecting the network developers looking can modify the network and construct the corpus with consideration of many features of medical English style.

\section{Acknowledgements}

Funded Project: 2014 Key Research Project of Ningxia Medical University Supported by: Teaching Research on Medical English Translation Writing Based on Automatic Writing Assessment System (Item No. XZ201405).

\section{References}

[1] Tang Jinlan, Wu Yian. Review on the Applied Research of Online English Writing Automatic Evaluation System [M]. Foreign Language Teaching and Research, 2011 (02)

[2] Tang Jinlan, Wu Yian. Application of Automatic Writing System in College English Teaching [J]. Foreign Language and Foreign Language Teaching. 2012 (04) 
[3] Zhang Yanhong. College English online writing teaching dynamic assessment model [J] Foreign Languages. 2008 (04)

[4] Cai Jing. A Review of Online Formative Assessment Applied in College English Writing Teaching in China [J]. Chinese Journal of Applied Linguistics. 2012 (04)

[5] Jiang Xueqing. Analysis of the automatic composition evaluation system for college students English writing ability development [J] Shandong Foreign Language Teaching. 2011 (06) 